DOI: $10.1002 /($ please add manuscript number $))$

Article type: Communication

\title{
Novel and Facile Route for the Synthesis of Tunable Boron Nitride Nanotubes Combining Atomic Layer Deposition and Annealing Processes for Water Purification
}

Matthieu Weber, Igor Iatsunskyi, Emerson Coy, Philippe Miele, David Cornu and Mikhael Bechelany*

Dr. M. Weber, Prof. P. Miele, Prof. D. Cornu, Dr. M. Bechelany

Institut Européen des membranes, IEM, UMR-5635, Univ Montpellier, CNRS, ENSCM, Montpellier, France

E-mail: mikhael.bechelany@umontpellier.fr

Prof. P. Miele

Institut Universitaire de France, 1 rue Descartes, 75231 Paris, France

Dr. I. Iatsunskyi, Dr. E. Coy,

NanoBioMedical Centre, Adam Mickiewicz University in Poznan, 61-614, Umultowska str.

85 Poznan, Poland

Keywords: Boron nitride, Atomic Layer Deposition, nanotubes, electrospinning, water purification

Abstract. The synthesis of tunable boron nitride nanotubes is the subject of intense research because of their potential applications in various fields, from smart textile materials to emerging environmental technologies. However, the preparation of these nanomaterials remains extremely challenging. Herein, we report proof-of-concept results on the scalable synthesis of boron nitride nanotubes with tunable dimensions. Combining atomic layer deposition (ALD) of boron nitride on carbon nanofibers template supports and successive annealing steps at high temperature, BN nanotubes with controllable properties have been prepared. The successive annealing steps enable the crystallization of $\mathrm{BN}$ and the combustion of the initial carbon supports. The self-limiting nature of the ALD process allows for the scalable coating of large scale carbon fibers matrix. High-resolution TEM measurements demonstrated the exquisite dimensions control at the nanoscale and the presence of crystalline BN. The proof-of-concept results presented allow for independent control of the inner and external diameter dimensions, opening up unique possibilities for the precise engineering of 
BN nanotubes properties. The nanotubes present good mechanical properties, are easy to handle, and the assessment of their sorption properties showed that they absorb up to 110 times their own weight in oils while repelling water, which opens prospects for water purification.

Boron nitride $(\mathrm{BN})$ nanomaterials are the focus of extensive research because of their exceptional physico-chemical properties. ${ }^{[1]}$ Depending on its polymorphic structure, this III-V material can exhibit great hardness, high thermal and chemical stability, electrical insulation and high shock resistance. ${ }^{[2]} \mathrm{BN}$ nanotubes based materials at the micro and nanoscale are the subject of attention because of their potential applications in various fields, from ultrafiltration to thermal management, and from smart textile materials to emerging applications in environmental technologies. ${ }^{[1 \mathrm{a}, 1 \mathrm{~b}, 3]}$ For example, one potential technological application of these nanomaterials is water purification. ${ }^{[4]}$ In fact, oil and organic solvents spillages due to heavy industries and accidents are primary water pollutants. Due to their good adsorption properties, boron nitride nanotubes are excellent candidates for the sorption of these pollutants and thus for water purification.

Different manufacturing routes already exist for the synthesis of sub-microscale BN nanotubes, ${ }^{[5]}$ such as chemical vapor deposition (CVD), ${ }^{[1 b, 6]}$ pyrolysis,${ }^{[7]}$ arc-discharge, ${ }^{[8]}$ laser ablation methods, ${ }^{[9]}$ chemical reduction routes, ${ }^{[10]}$ plasma processes ${ }^{[11]}$ or template assisted processes. ${ }^{[12]}$ However, traditional synthesis methods often lack precise control of the BN nanotubes dimensions. It is thus much desirable to develop a scalable, robust and versatile process for the production of $\mathrm{BN}$ nanotubes with tunable sizes.

Atomic layer deposition (ALD) is a vapor phase technique, nowadays considered as the method of choice to deposit conformal ultrathin films of a wide variety of materials for a growing number of applications. ${ }^{[13]}$ The self-limiting surface chemistry taking place during 
the alternating precursor and co-reactant pulses allows the film growth to be controllable at the atomic level. Thus, this technology is particularly suited to deposit ultrathin films with controllable thickness on complex $3 \mathrm{D}$ substrates. ${ }^{[13 \mathrm{f}, 14]}$ For example, ultrathin layers of $\mathrm{Al}_{2} \mathrm{O}_{3}$ were deposited conformally onto carbon fibers using ALD. ${ }^{[15]}$

Very recently, Hao et al. reported the preparation of $\mathrm{BN}$ nanotubes using a "ALD-like" process based on polymer derived ceramics (PDCs) chemistry and achieved excellent oil absorption capacities of $11000 \% .{ }^{[4 c, 16]}$ However, the first process step consisting of depositing a pre-ceramic polymer layer was based on an unstable and home-synthesized borazine derivative precursor not available on the market. Furthermore, the need for a second 'densification' step at high temperature to convert the material to the desired ceramic makes the dimensions of the $\mathrm{BN}$ nanomaterial more difficult to control, especially when compared to a conventional ALD route.

Herein, we report a strategy for the preparation of tunable BN nanotubes that overcomes these limitations, using an innovative new route based on ALD. The preparation of BN thin films by ALD is challenging, but several successful processes making use of precursors widely available have been reported recently, that enabled for the deposition of controllable BN films with high uniformity and conformality. ${ }^{[13 c, 17]}$ By combining an ALD of BN process on chosen carbon nanofibers supports and annealing steps under successive nitrogen and oxygen atmospheres, BN nanotubes with controllable diameters at the nanoscale have been prepared. The tuning of the diameters by varying the number of cycles and the presence of hexagonal BN (h-BN) microstructure are revealed by high-resolution Transmission Electron Microscopy (TEM) studies. Furthermore, the easy handling of the nanomaterials prepared enabled the sorption performances of the BN nanotubes to be assessed, and the excellent results obtained open prospects for water purification.

ALD enables the deposition of very conformal ultrathin films on complex 3D substrates. An ALD process has been developed and employed in order to deposit the $\mathrm{BN}$ thin films. 
Basically, the process consisted of sequential exposures of boron tribromide precursor $\left(\mathrm{BBr}_{3}\right)$ and $\mathrm{NH}_{3}$ gas, separated by purge steps of Argon. The detailed parameters of this process are given in the Experimental section and more information can be found elsewhere. ${ }^{[13 c]}$ Carbon nanofibers templates have been synthesized using an electrospinning process and used as supports (see Experimental section for details). The BN films have been prepared on silicon with native oxide substrates in parallel in order to ensure the success of the ALD process. As can be depicted from Figure 1a, this process leads to steady-state ALD growth of $\sim 0.8$ $\AA ̊ \AA$ cycle (as measured by spectroscopic ellipsometry on $\mathrm{Si}$ substrates), with no visible nucleation delay.

The linearity of the ALD process permits to choose the thickness of the films prepared by simply varying the number of cycles applied (Figure 1a). Next, the material properties of the BN films synthesized ( $25 \mathrm{~nm}$ thick on silicon substrates) using this process have been defined. The films synthesized were smooth, presented low contamination levels, a turbostratic microstructure and a mass density of $2.2 \pm 0.3 \mathrm{~g} / \mathrm{cm}^{3}$. More complete studies on the BN material properties have already been carried out and reported elsewhere. ${ }^{[13 c, 18]}$ The material properties are presented in details in Supporting Information (Table S1). It is important to mention that we previously studied and reported the evolution of mechanical properties and microcrystallinity of the $\mathrm{BN}$ films as a function of temperature. ${ }^{[18]}$

We used this BN ALD process to coat the electrospun carbon nanofibers template supports by applying different numbers of cycles, and directly carried out successive annealing steps at high temperature. Please note that the carbon nanofibers template supports can be chosen according to the structure and application, as the inner diameter of the $\mathrm{BN}$ tubes will be defined by the initial carbon nanofibers dimensions. For example, the use of single wall or multiwall carbon nanotubes as initial supports would lead to smaller inner diameters than the ones obtained in this work, as the electrospun carbon nanofibers used present diameters in the range of 100-200 $\mathrm{nm}$. In fact, multilayered and functionalized ALD coatings can also be 
deposited conformally on carbon nanotubes. ${ }^{[19]}$ Furthermore, BN coated carbon fibers matrix are also very promising materials for high performance composites, especially in terms of wear life, strength and oxidation resistance. ${ }^{[20]}$

After the first ALD step, in order to obtain the crystallization of the BN coatings, the samples were placed 5 hours at a temperature of $1350{ }^{\circ} \mathrm{C}$ in pure nitrogen atmosphere. This annealing step enables the formation of $h$-BN crystallites and the removal of potential defects in the microstructure. Next, in order to eliminate the carbon material from the initial supports, the samples were annealed in air for 4 hours at $600{ }^{\circ} \mathrm{C}$. This annealing treatment is ideally suited because it enables to convert the carbon to $\mathrm{CO}_{2}$, leaving solely the $\mathrm{BN}$ nanomaterials.

Figure $1 \mathrm{~b}$ and $1 \mathrm{c}$ illustrate the preparation of these nanomaterials. These figures present photographs of a sample consisting of carbon fibers coated with a layer of approximately 20 $\mathrm{nm}$ of BN obtained by applying 250 ALD cycles, before and after the annealing steps. The difference between Figure $1 \mathrm{~b}$ and $1 \mathrm{c}$ is clearly visible, as the color of the sample (Figure 1b) drastically changed from black to white (Figure 1c), depicting the combustion of the carbon material. It is important to note that the resulting self-supported $\mathrm{BN}$ nanotubes possess good mechanical properties and are easy to handle. SEM measurements have been carried out in order to gain understanding on the morphology of the fibers obtained in Figure 1c. The BN nanotubes obtained are visible as a white "fabric-like structure", as can be seen in the SEM image shown in Figure 1d as well as in the Supporting Information (S2).

Next, high-resolution TEM imaging has been carried out on the BN nanotubes in order to confirm the control of their dimensions and investigate their microstructure.

The first observations are that straight nanotubes are obtained and that the tubular shape is clearly visible for all samples, as can be seen in Figure 2a and 2e. This illustrates the fact that the BN coatings are uniform, thanks to the self-limiting nature of ALD. In particular, Figure $2 \mathrm{~d}$ shows a number of nanotubes were the uniformity of the coatings can be clearly observed. Next, one can also see that the diameter of the tubes can be tuned simply by varying the 
number of cycles. In Figure 2a-e, the tubes imaged present wall thicknesses from approximately 3, 20and $80 \mathrm{~nm}$, corresponding to 20, 250 and 1000 ALD cycles, respectively. The diameters obtained on the carbon fibers are in line with the $\mathrm{BN}$ growth per cycle of 0.08 $\mathrm{nm}$ measured on silicon substrates, as depicted in Figure S2 where the wall thickness of the nanotubes and the thickness of the films on Si substrates as a function of the number of ALD cycles is given. This demonstrates the precise control of the nanotube dimensions (at the nanometer level) that this new route provides. Furthermore, the high-resolution TEM images in Figure $2 \mathrm{a}$ and $2 \mathrm{f}$ show crystalline microstructures related to $h$ - $\mathrm{BN}$ and clear $\mathrm{BN}$ bonding, as the lattice fringes are clearly visible. Using Fast Fourier Transform (FFT), (see inset in Figure 2f), we determined the interplanar distances of $0.32,0.21$ and $0.17 \mathrm{~nm}$ for $h$-BN (JCPDS 01-073-2095), which correspond to the lattice distances of (002), (100) and (004) planes, respectively. ${ }^{[21]}$ Interestingly, the crystallization behavior is different for nanotubes with different diameters. The samples with the "large" wall thickness of $80 \mathrm{~nm}$ prepared using 1000 cycles present the typical turbostratic microstructure observed when preparing $\mathrm{BN}$ thin films by $\mathrm{ALD},{ }^{[13 c, 18,22]}$ showing different directions of the lattice fringes, whereas well aligned and crystalline hexagonal BN layers oriented along the nanotube axis can clearly be seen for the nanotubes with the smallest $3 \mathrm{~nm}$ wall thickness (Figure 2a). In fact, the HRTEM image of the multiwall nanotubes presented in Figure 2a shows that the BN layers are separated by a distance of $\sim 0.34 \mathrm{~nm}$ (typical of graphitic layer of $\mathrm{BN}$ ). The perfect crystallization observed for ultra-thin diameters is in line with the $h$-BN growth witnessed for some other ALD BN processes, which have been reported solely for one (mono) or a few BN layers. ${ }^{[17,23]}$ One hypothesis explaining this difference is that the morphological feature and size constrain present in the $\mathrm{BN}$ nanotubes with the smallest diameters must make its crystallization behavior different from the larger diameter (more like "bulk") tubes. This could be explained by two phenomena. First the growth is affected by the interaction with the carbon surface for the first monolayers, and the growth of 002 basal planes is more favorable 
along the carbon nanofibers. Indeed, for larger diameters and more "bulk" like layers, the expansion of dislocations with the thickness increment, ${ }^{[24]}$ leads to the observed turbostratic microstructure. Such transition between hexagonal and turbostratic BN with the increasing of thickness has been already described by Cao et al. ${ }^{[25]}$ This behavior could be attributed to another phenomenon: the heat treatment at $1350^{\circ} \mathrm{C}$ can induce an increase of the strain on the interface between the carbon nanofibers and the deposited boron nitride thin film. This strain could enhance the orientation and the crystallization of thin boron nitride films in comparison to the bulk coating. This observation is also in line with our previous crystallographic study of BN films prepared by ALD, which results suggested that the highest concentration of the $h$ $\mathrm{BN}$ phase is present in the deepest part of the films, whereas the secondary phases are present everywhere in the films. ${ }^{[18]}$ As an additional remark, we have to mention that the $3 \mathrm{~nm}$ coating layer is not thick enough to perfectly keep the tubular structure of the nanofibers used as initial skeleton (as shown in Figure 2b). However, as the morphology and the general concentric layers of the nanotubes obtained show strong similarity to multiwall carbon nanotubes (MWCNTs), we believe that by further tuning the initial fibers diameter or by using directly MWCNTs, stable and well aligned MWBNNTs can be obtained.

The proof-of-concept presented showed that the facile and scalable formation of $\mathrm{BN}$ nanotubes can be achieved. It is important to note that this new route allows for the control of the inner diameter - by carefully choosing the initial carbon supports (e.g. fibers, single wall or multiwall carbon nanotubes) - and of the $\mathrm{BN}$ diameter thanks to the self-limiting nature of the ALD process. This new process thus allows for independent control of the inner and external diameter dimensions, opening up unique possibilities for precise engineering of $\mathrm{BN}$ nanotubes properties.

Next, in order to illustrate the applicability of the synthesized nanotubes, we performed initial experiments on oil and organic solvent (ethylene glycol) absorption. We used the experimental approach described by Lei et al. ${ }^{[4 a]}$ and Song et al. ${ }^{[26]}$ in order to measure the 
weight absorption capacity of the tubes prepared. Briefly, the BN nanomaterials samples are dropped in a water-oil/solvent solution and, being hydrophobic, ${ }^{[13 c]}$ directly absorb the oil/solvent while repelling the water. The saturated samples float on the surface and are therefore easily removed and weighed. In addition, it has been shown that BN nanomaterials can be reused by simply burning them in air to remove the absorbed organics. ${ }^{[4 a]}$

Figure 3 shows the uptakes of (pump) oil and ethylene glycol by the BN nanotubes prepared (using 250 ALD cycles and the annealing steps, nanotubes presenting wall thickness of approximately $20 \mathrm{~nm}$ ), compared with relevant data obtained by using similar nanomaterials.

The results obtained showed that the BN nanotubes absorb up to 110 times their weight in oil and 135 times their weight in ethylene glycol. These values are in the same order of magnitude as the ones recently reported in the literature for porous $\mathrm{BN}$ nanotubes, ${ }^{[16]}$ nanosheets ${ }^{[4 \mathrm{a}]}$ and $\mathrm{BN}$ aerogels. ${ }^{[26]}$ The fact that they present such a high absorbance for pollutants and that the saturated nanomaterials can be easily removed and reused, makes them very attractive for depollution purposes, particularly for water purification. Furthermore, even if the absorption is in the same order of magnitude as previously reported results, the selfsupported BN nanotubes synthesized in this work are easy to handle, and are expected to present higher mechanical stability than nanosheets or aerogels.

In summary, we reported the scalable synthesis of $\mathrm{BN}$ nanotubes that can be tuned in terms of diameters dimensions through a novel and easy route combining ALD and annealing steps. Carbon nanofibers templates are used as initial supports. In order to obtain the crystallization of $\mathrm{BN}$ and to eliminate the carbon initial supports, the samples were first placed at a temperature of $1350{ }^{\circ} \mathrm{C}$ in nitrogen atmosphere for 5 hours, and then annealed at $600{ }^{\circ} \mathrm{C}$ for 4 hours in air. The inner diameter can be controlled by choosing the initial carbon nanofibers supports. High resolution TEM imaging has been carried out to characterize the obtained BN nanotubes. The self-limiting reactions of ALD provide a clear control over the diameter 
thickness of the BN layer deposited with sub-nanometer accuracy as a steady-state ALD growth of $\sim 0.8 \AA$ Acycle has been observed on all our samples.

Interestingly, the crystallization behavior is different for nanotubes with different diameters. The samples with the "large" wall thickness of $80 \mathrm{~nm}$ presented the typical turbostratic microstructure whereas well aligned and crystalline $h$-BN layers oriented along the nanotube axis have been revealed for the nanotubes with the smallest $3 \mathrm{~nm}$ wall thickness, which was attributed to the fact that growth is governed by the interaction with carbon fibers for the first layers and that this crystallization is enhanced during the thermal treatment due the induced strain.

The self-supported BN nanotubes synthesized present good mechanical properties and are easy to handle. Furthermore, the sorption performances of the $\mathrm{BN}$ nanotubes have been assessed, and the results showed that the nanotubes absorb up to 110 times their weight in oil while repelling water. The proof-of-concept results presented, allowing for the easy synthesis of BN nanotubes with a dimensions control at the nanometer level, are thus very promising for water purification purposes.

\section{Experimental Section}

Atomic Layer deposition of BN. All depositions were carried out on $\mathrm{Si}(100)$ substrates under a base pressure of $1.10^{-2}$ mbar. Boron tribromide $\left(\mathrm{BBr}_{3}\right)$ precursor was purchased from Sigma Aldrich and used as received. The co-reactant was ammonia gas. ALD of BN was achieved using sequential exposures of $\mathrm{BBr}_{3}$ and $\mathrm{NH}_{3}$ separated by purge steps of Argon with a flow rate of $100 \mathrm{sccm}$. If not stated otherwise, the typical ALD cycle consisted of $0.1 \mathrm{~s}$ pulse of $\mathrm{BBr}_{3}, 25 \mathrm{~s}$ exposure, and $30 \mathrm{~s}$ purge, followed by a $3 \mathrm{~s}$ pulse of $\mathrm{NH}_{3}, 25 \mathrm{~s}$ exposure and $30 \mathrm{~s}$ purge with Argon.

In order to develop and characterize the ALD process, silicon with native oxide substrates were used. The p-type (100) silicon wafers were purchased from MEMC Korea Company. To 
remove the organic contaminants, the substrates were pre-cleaned in acetone, ethanol and deionized water for $5 \mathrm{~min}$ in ultrasonic bath before the depositions.

The carbon fibers supports were synthesized following a process described elsewhere. ${ }^{[27]}$ Briefly, PAN fibers were synthesized using an electrospinning process. A PAN solution in DMF (10 wt\%) was stirred at $70{ }^{\circ} \mathrm{C}$ for 6 hours and electrospun under high voltage. The fibers were synthesized between a needle and a stationary disc covered with aluminum. The tip to collector distance was approximately $14 \mathrm{~cm}$. The electrospun PAN nanofibers were then stabilized in air at $250{ }^{\circ} \mathrm{C}$ for $2 \mathrm{~h}$ before being carbonized at $1200^{\circ} \mathrm{C}$ ( $1 \mathrm{~h}$ dwell) in nitrogen atmosphere (heating rate $2{ }^{\circ} \mathrm{C} \min ^{-1}$ ), yielding the electrospun carbon fibers desired.

The ALD reactor used was a hot-wall horizontal flow-type ALD (home-built) reactor. The $\mathrm{BBr}_{3}$ precursor was contained in a bubbler connected to the inlet of a pneumatic valve, and metal gaskets were employed for seal fittings. On the vacuum line, there was one additional valve to isolate the chamber from the vacuum pump (this valve is used as a stop valve for the ALD exposure mode). Finally, the gases go into the mechanical vacuum pump as the exhaust, which allowed for a reactor base pressure of $1.10^{-2}$ mbar. Computer-controlled mass flow controllers and pneumatic valves monitor the ALD process. If not specified otherwise, the lines were heated at $100{ }^{\circ} \mathrm{C}$ to avoid condensation and the deposition reactor was set at a temperature of $750^{\circ} \mathrm{C}$.

Annealing. In order to crystallize the boron nitride coatings and to eliminate the carbon materials, the samples were annealed in successive nitrogen and oxygen atmospheres.

In order to obtain the crystallization of $\mathrm{BN}$, the samples were first placed 5 hours at a temperature of $1350{ }^{\circ} \mathrm{C}$ in nitrogen atmosphere, and the temperature was reached at a rate of $300 \mathrm{~K} /$ hour. Next, to eliminate the carbon initial supports, the samples were annealed in air for 4 hours at $600{ }^{\circ} \mathrm{C}$, and the temperature was reached at the same rate of $300 \mathrm{~K} / \mathrm{hour}$.

Characterizations. To evaluate the BN film thickness after the ALD depositions on silicon substrates, ex-situ spectroscopic ellipsometry (SE) measurements were carried out using a 
Semilab GES5E visible ellipsometer $(1.2-5.0 \mathrm{eV})$ at an angle of incidence of $70.2^{\circ}$. For all the films, the empirical Cauchy dispersion formula has been adopted to model the optical properties and the thicknesses. The composition of the films was analyzed by X-ray photoelectron spectroscopy (XPS) on a SPECS Sage HR 100 spectrometer with a non monochromatic $\mathrm{X}$ ray source (Aluminum $\mathrm{K} \alpha$ line of $1486.6 \mathrm{eV}$ energy). The microstructure and the density of the films were determined by X-ray diffraction and reflectometry (GIXRDXRR) using a Panalyitical X'pert 3 system. A JEOL ARM 200F high-resolution transmission electron microscope at $200 \mathrm{kV}$ has been used for the high resolution TEM and SEM studies (JEOL, JSM-7001F).

Organic solvent and oil sorption assessment. Ethylene glycol and (pump) oil were used in this study. The assessment of the sorption was carried out following experimental procedures reported by others. ${ }^{[4 a, 26]}$ Briefly, the absorption capacity values (wt/wt)\% were obtained by measuring the mass of the dry nanotubes, and then the mass after ethylene glycol / oil absorption. The samples were left immerged in the ethylene glycol or oil fully for 12 hours to ensure full saturation was obtained before weighting. The measurements were achieved rapidly to avoid evaporation of the absorbed oils or solvents.

\section{Supporting Information}

Supporting Information is available from the Wiley Online Library or from the author.

\section{Acknowledgements}

This work was supported by the French Research Programs ANR BONALD and ANR MeNiNa. The supports of the COST Action "HERALD", a European cooperation program, is acknowledged.

Received: ((will be filled in by the editorial staff))

Revised: ((will be filled in by the editorial staff)) Published online: ((will be filled in by the editorial staff))

\section{References}


[1] a) M. Terrones, J. Romo-Herrera, E. Cruz-Silva, F. López-Urías, E. Munoz-Sandoval, J. Velázquez-Salazar, H. Terrones, Y. Bando, D. Golberg, Materials today 2007, 10, 30; b) D. Golberg, Y. Bando, C. Tang, C. Zhi, Advanced Materials 2007, 19, 2413; c) S. Bernard, V. Salles, J. P. Li, A. Brioude, M. Bechelany, U. B. Demirci, P. Miele, J. Mater. Chem. 2011, 21, 8694.

[2] a) Y. Tian, B. Xu, D. Yu, Y. Ma, Y. Wang, Y. Jiang, W. Hu, C. Tang, Y. Gao, K. Luo, Nature 2013, 493, 385; b) Y. Zhu, Y. Bando, L. Yin, D. Golberg, Nano letters 2006, 6, 2982; c) C. Jin, F. Lin, K. Suenaga, S. Iijima, Physical review letters 2009, 102, 195505; d) S. Yuan, S. Benayoun, A. Brioude, O. Dezellus, B. Beaugiraud, B. Toury, Journal of the European Ceramic Society 2013, 33, 393.

[3] V. Salles, S. Bernard, A. Brioude, D. Cornu, P. Miele, Nanoscale 2010, 2, 215.

[4] a) W. Lei, D. Portehault, D. Liu, S. Qin, Y. Chen, Nature communications 2013, 4, 1777; b) T. A. Hilder, D. Gordon, S. H. Chung, Small 2009, 5, 2183; c) W. Hao, C. Journet, A. Brioude, ChemNanoMat 2017, 3, 656; d) C. Y. Won, N. Aluru, Journal of the American Chemical Society 2007, 129, 2748; e) T. T. Li, L. J. Wang, K. Zhang, Y. C. Xu, X. Y. Long, S. J. Gao, R. Li, Y. G. Yao, Small 2016, 12, 4960.

[5] a) L. J. Wang, T. T. Li, L. Ling, J. Luo, K. Zhang, Y. C. Xu, H. F. Lu, Y. G. Yao, Chemical Physics Letters 2016, 652, 27; b) L. J. Wang, T. T. Li, X. Y. Long, X. N. Wang, Y. C. Xu, Y. G. Yao, Nanoscale 2017, 9, 1816; c) E. Songfeng, X. Y. Long, C. W. Li, R. J. Geng, D. B. Han, W. B. Lu, Y. G. Yao, Chemical Physics Letters 2017, 687, 307; d) E. Songfeng, L. Chaowei, L. Taotao, G. Renjie, L. Qiulong, L. Weibang, Y. Yagang, Nanotechnology 2018; e) L. J. Wang, D. B. Han, J. Luo, T. T. Li, Z. Y. Lin, Y. G. Yao, Journal of Physical Chemistry C 2018, 122, 1867.

[6] a) C. Tang, Y. Bando, T. Sato, K. Kurashima, Chemical Communications 2002, 1290; b) C. H. Lee, J. Wang, V. K. Kayatsha, J. Y. Huang, Y. K. Yap, Nanotechnology 2008, 19, 455605; c) M. Bechelany, A. Brioude, S. Bernard, P. Stadelmann, D. Cornu, P. Miele, CrystEngComm 2011, 13, 6526.

[7] R. Sen, B. Satishkumar, A. Govindaraj, K. Harikumar, G. Raina, J.-P. Zhang, A. Cheetham, C. Rao, Chemical Physics Letters 1998, 287, 671.

[8] J. Cumings, A. Zettl, Chemical Physics Letters 2000, 316, 211.

[9] T. Laude, Y. Matsui, A. Marraud, B. Jouffrey, Applied Physics Letters 2000, 76, 3239.

[10] a) T. Bartnitskaya, G. Oleinik, A. Pokropivnyi, V. Pokropivnyi, Jetp Letters 1999, 69, 163; b) M. Bechelany, A. Brioude, P. Stadelmann, S. Bernard, D. Cornu, P. Miele, The Journal of Physical Chemistry C 2008, 112, 18325.

[11] C. M. Lee, S. Choi, S. Choi, S. H. Hong, Current Applied Physics 2006, 6, 166.

[12] M. Bechelany, S. Bernard, A. Brioude, D. Cornu, P. Stadelmann, C. Charcosset, K. Fiaty, P. Miele, The Journal of Physical Chemistry C 2007, 111, 13378.

[13] a) S. M. George, Chemical Reviews 2010, 110, 111; b) J. Hamalainen, M. Ritala, M. Leskela, Chemistry of Materials 2014, 26, 786; c) M. Weber, B. Koonkaew, S. Balme, I. Utke, F. Picaud, I. Iatsunskyi, E. Coy, P. Miele, M. Bechelany, Acs Applied Materials \& Interfaces 2017 9, 16669; d) M. J. Weber, M. A. Verheijen, A. A. Bol, W. M. M. Kessels, Nanotechnology 2015, 26, 094002; e) C. Marichy, M. Bechelany, N. Pinna, Advanced Materials 2012, 24, 1017; f) M. Leskelä, M. Ritala, Angewandte Chemie International Edition 2003, 42, 5548; g) M. Pavlenko, E. Coy, M. Jancelewicz, K. Załęski, V. Smyntyna, S. Jurga, I. Iatsunskyi, RSC Advances 2016, 6, 97070.

[14] a) M. Leskelä, M. Ritala, Thin solid films 2002, 409, 138; b) M. Ritala, M. Leskela, J.P. Dekker, C. Mutsaers, P. J. Soininen, J. Skarp, Chem. Vap. Deposition 1999, 5, 7.

[15] A. Roy, W. Baumann, I. König, G. Baumann, S. Schulze, M. Hietschold, T. Mäder, D. Nestler, B. Wielage, W. Goedel, Analytical and bioanalytical chemistry 2010, 396, 1913. 
[16] W. Hao, C. Marichy, A. Brioude, Environmental Science: Nano 2017, 4, 2311.

[17] H. Park, T. K. Kim, S. W. Cho, H. S. Jang, S. I. Lee, S.-Y. Choi, Scientific reports 2017, 7, 40091.

[18] Matthieu Weber, Emerson Coy, Igor Iatsunskyi, Luis Yate, Philippe Miele, M. Bechelany, CrystEngComm 2017, 19, 6089.

[19] a) C. F. Herrmann, F. H. Fabreguette, D. S. Finch, R. Geiss, S. M. George, Applied Physics Letters 2005, 87; b) D. B. Farmer, R. G. Gordon, Nano letters 2006, 6, 699.

[20] a) S. Seghi, J. Lee, J. Economy, Carbon 2005, 43, 2035; b) B. Pan, N. Li, R. Huang, N. Li, R. Huang, W. Zhou, Y. Liu, Y. Zhang, Polymer-Plastics Technology and Engineering 2015, 54, 625; c) M. Das, A. Basu, S. Ghatak, A. G. Joshi, Journal of the European Ceramic Society 2009, 29, 2129.

[21] S. Yuan, S. Linas, C. Journet, P. Steyer, V. Garnier, G. Bonnefont, A. Brioude, B. Toury, Scientific reports 2016, 6.

[22] a) J. Olander, L. M. Ottosson, P. Heszler, J. O. Carlsson, K. M. Larsson, Chemical Vapor Deposition 2005, 11, 330; b) B. Mårlid, M. Ottosson, U. Pettersson, K. Larsson, J.-O. Carlsson, Thin solid films 2002, 402, 167.

[23] a) A. Haider, C. Ozgit-Akgun, E. Goldenberg, A. K. Okyay, N. Biyikli, Journal of the American Ceramic Society 2014, 97, 4052; b) A. Hemmi, C. Bernard, H. Cun, S. Roth, M. Klöckner, T. Kälin, M. Weinl, S. Gsell, M. Schreck, J. Osterwalder, Review of Scientific Instruments 2014, 85, 035101.

[24] Y. Kobayashi, T. Akasaka, Journal of Crystal Growth 2008, 310, 5044.

[25] L. M. Cao, X. Y. Zhang, H. Tian, A. Zhang, W. K. Wang, Nanotechnology 2007, 18, 155605.

[26] Y. Song, B. Li, S. Yang, G. Ding, C. Zhang, X. Xie, Scientific reports 2015, 5.

[27] a) A. Both Engel, M. Bechelany, O. Fontaine, A. Cherifi, D. Cornu, S. Tingry, ChemElectroChem 2016, 3, 629; b) A. Both Engel, A. Cherifi, M. Bechelany, S. Tingry, D. Cornu, ChemPlusChem 2015, 80, 494. 

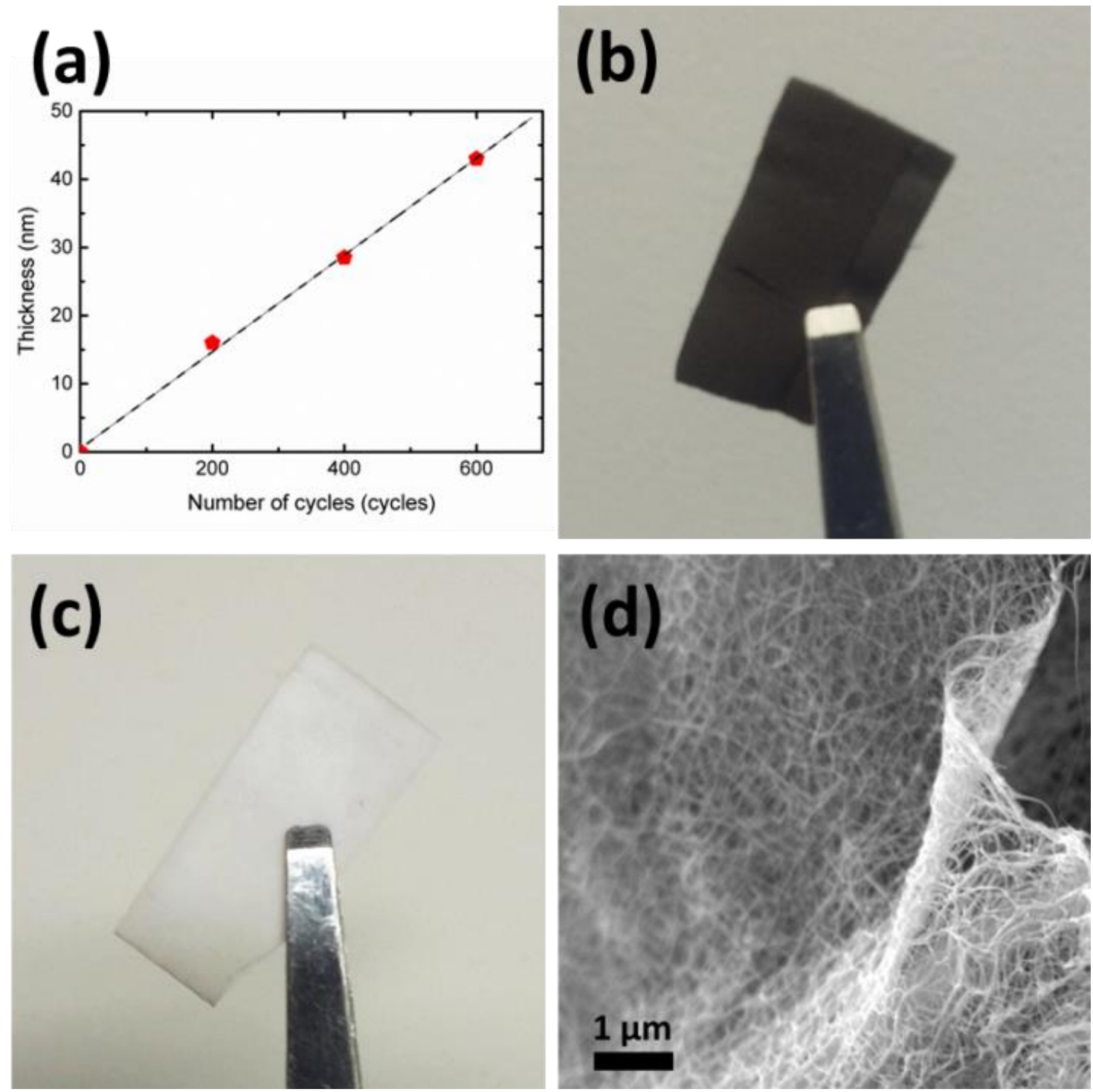

Figure 1. (a) Thickness of the BN films as a function of the number of ALD cycles on silicon substrates, as determined by spectroscopic ellipsometry. The line serves as a guide to the eyes. (b) Photograph of a sample consisting of carbon fibers coated with $20 \mathrm{~nm}$ of BN by applying 250 ALD cycles before the annealing steps and (c) after the annealing steps. (d) Corresponding SEM image. 

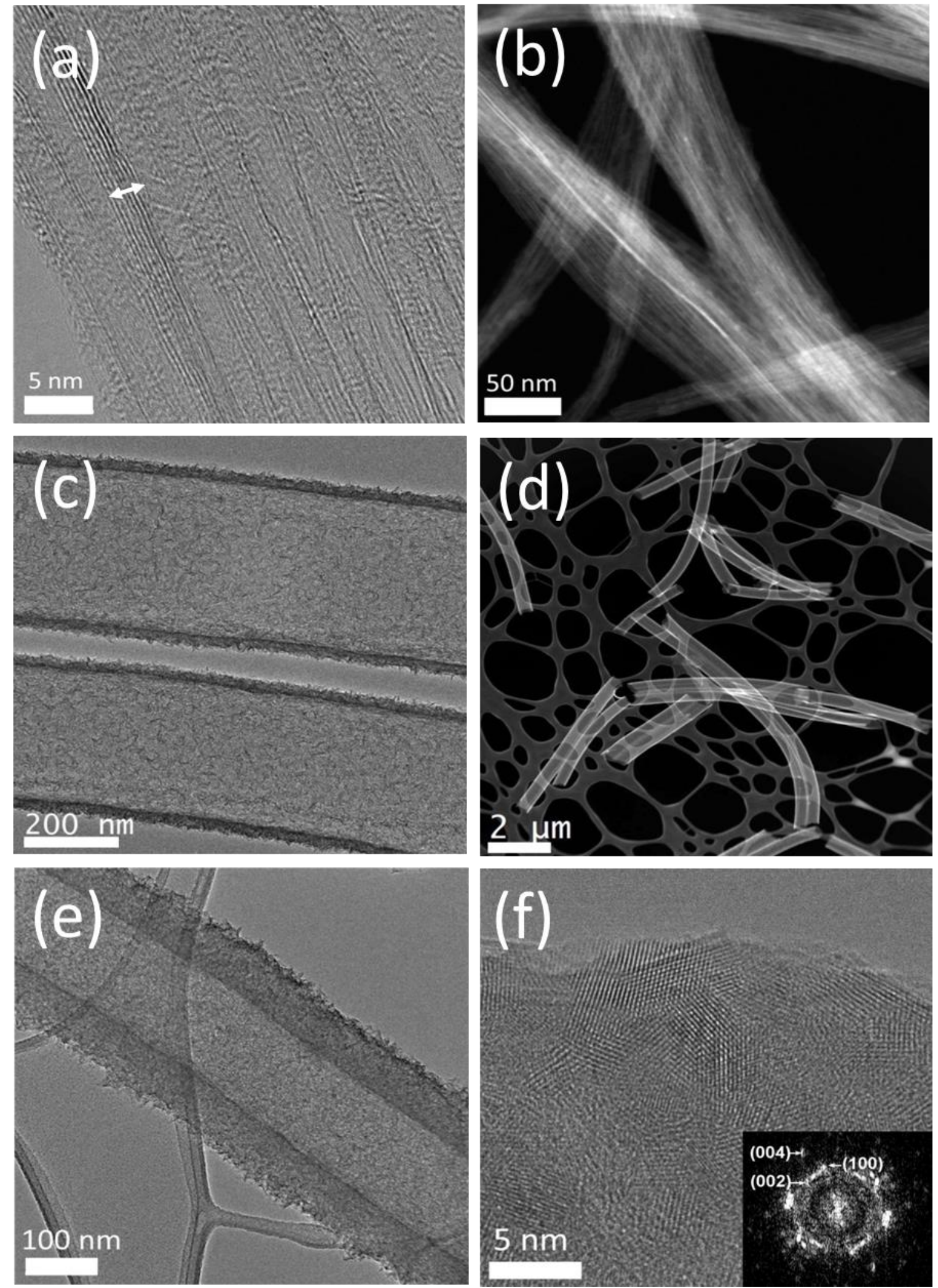

Figure 2. High resolution TEM images of BN nanotubes prepared by combining ALD and annealing processes. Samples synthesized with different wall thicknesses have been imaged: (a,b) correspond to approximately $3 \mathrm{~nm}$ (20 ALD cycles), (c,d) to $20 \mathrm{~nm}$ (250 ALD cycles) and (e,f) to $80 \mathrm{~nm}$ (1000 ALD cycles), respectively. The inset in (f) presents the corresponding FFT. 


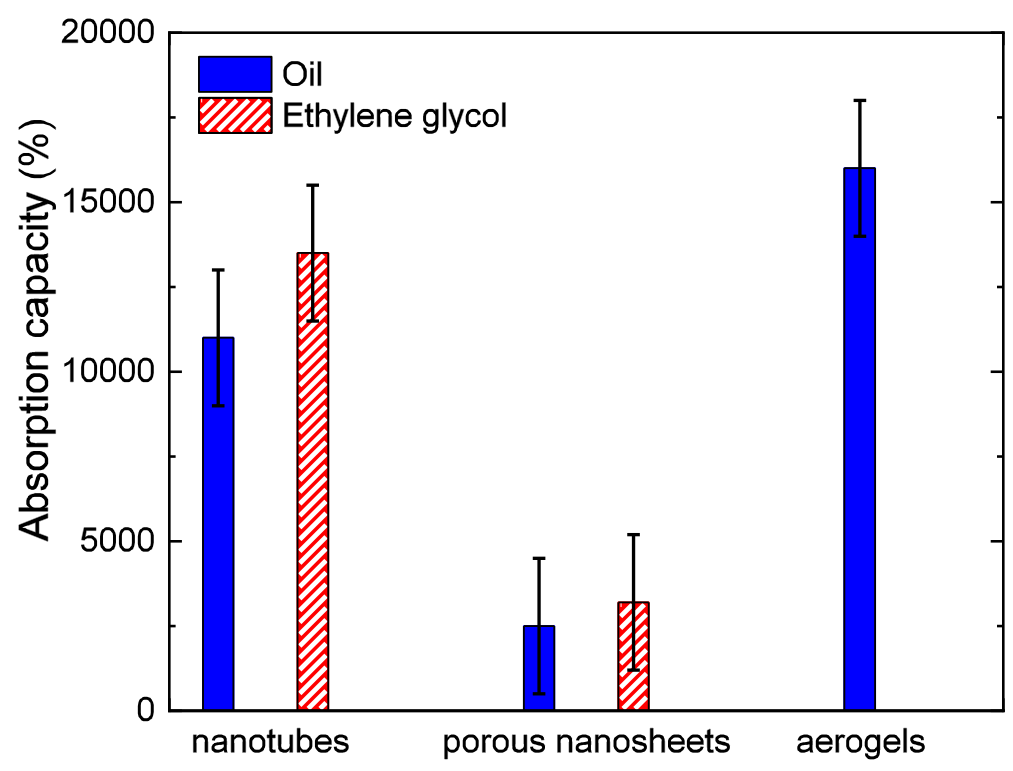

Figure 3. (a) Gravimetric absorption capacities of the porous BN nanotubes synthesized for (pump) oil and ethylene glycol, compared with relevant data from the literature for porous BN nanosheets $^{[4 \mathrm{a}]}$ and $\mathrm{BN}$ aerogels. ${ }^{[26]}$ 
We report a novel route for the scalable synthesis of boron nitride nanotubes with tunable dimensions. Combining atomic layer deposition (ALD) on carbon nanofibers supports and successive annealing steps, the independent control of the inner and external diameter of BN nanotubes dimensions have been achieved, opening up prospects for water purification.

Keywords: Boron nitride, Atomic Layer Deposition, nanotubes, electrospinning, water purification

M. Weber, I. Iatsunskyi, E. Coy, P. Miele, D. Cornu and M. Bechelany*

Novel and Facile Route for the Synthesis of Tunable Boron Nitride Nanotubes Combining Atomic Layer Deposition and Annealing Processes for Water Purification




Copyright WILEY-VCH Verlag GmbH \& Co. KGaA, 69469 Weinheim, Germany, 2016.

\section{Supporting Information}

Novel and Facile Route for the Synthesis of Tunable Boron Nitride Nanotubes Combining Atomic Layer Deposition and Annealing Processes for Water Purification

Matthieu Weber, Igor Iatsunskyi, Emerson Coy, Philippe Miele, David Cornu and Mikhael Bechelany*

Table S1. Properties of BN films prepared by ALD using $\mathrm{BBr}_{3}$ as precursor and $\mathrm{NH}_{3}$ as coreactant at $750^{\circ} \mathrm{C}$. The substrates were $\mathrm{Si}(100)$ wafers and the substrate temperature was $750^{\circ} \mathrm{C}$. In situ spectroscopic ellipsometry (SE), X-Ray reflectometry (XRR), atomic force microscopy (AFM), X-Ray photoelectron spectroscopy (XPS) and sessile drop technique (SDP) measurements were used for the analysis. The films were $25 \mathrm{~nm}$ thick for all analysis except for $\mathrm{Er}$ and $\mathrm{H}$ measurements where the thickness was around $80 \mathrm{~nm}$.

\begin{tabular}{|c|c|c|}
\hline Properties & Value & Analysis technique \\
\hline $\begin{array}{c}\text { Growth-per-cycle } \\
(\dot{A} / \text { cycle })\end{array}$ & $0.8 \pm 0.1$ & SE \\
\hline $\begin{array}{l}\text { Mass density } \\
\left(\mathrm{g} / \mathrm{cm}^{3}\right)\end{array}$ & $2.2 \pm 0.3$ & XRR \\
\hline $\begin{array}{c}\text { RMS roughness } \\
(\mathrm{nm})\end{array}$ & $3.5 \pm 2$ & AFM \\
\hline $\begin{array}{l}C \text { content } \\
\text { (at. } \%)\end{array}$ & $4 \pm 3$ & XPS \\
\hline $\begin{array}{l}O \text { content } \\
\text { (at. } \%)\end{array}$ & $7 \pm 3$ & XPS \\
\hline $\begin{array}{l}\text { Wetting } \\
\left({ }^{\circ}\right)\end{array}$ & $81 \pm 3$ & SDP \\
\hline $\begin{array}{c}\text { modulus of elasticity Er } \\
\text { (GPa) }\end{array}$ & $109 \pm 10$ & Nanoindentation \\
\hline $\begin{array}{l}\text { Hardness } \\
\text { (GPa) }\end{array}$ & $5.3 \pm 0.6$ & Nanoindentation \\
\hline
\end{tabular}




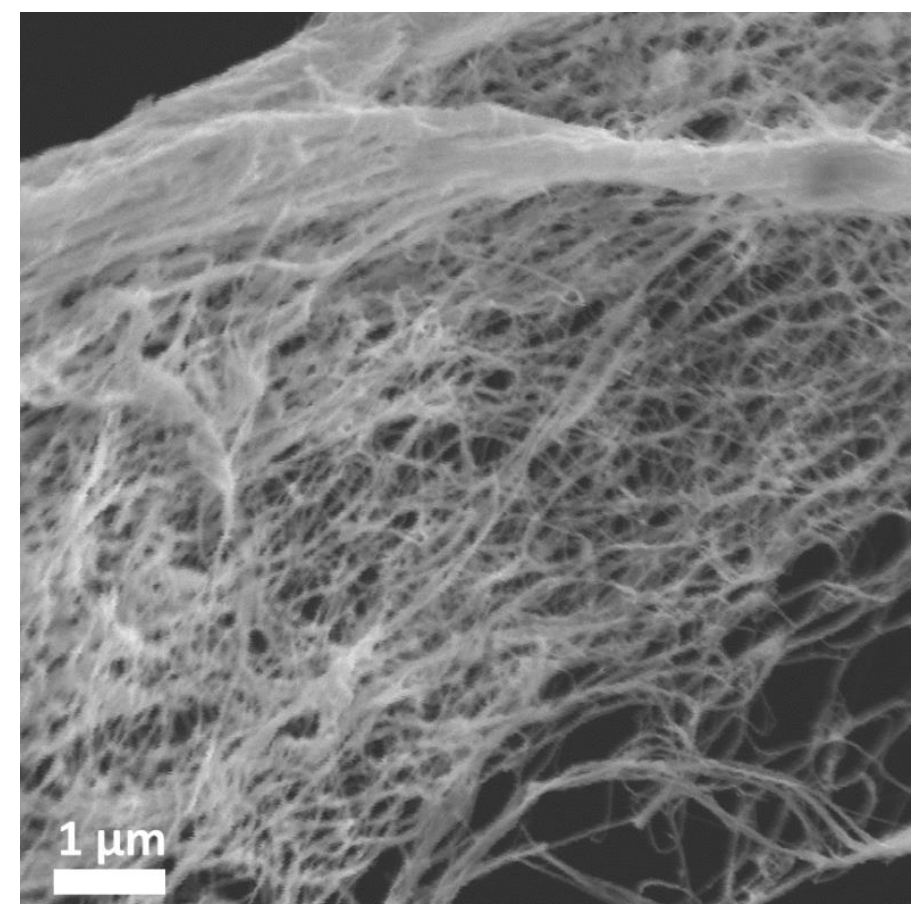

Figure S1. SEM image of self-supported BN nanotubes obtained after 250 ALD cycles and the annealing steps. The BN nanotubes obtained are visible as a white "fabric-like structure".

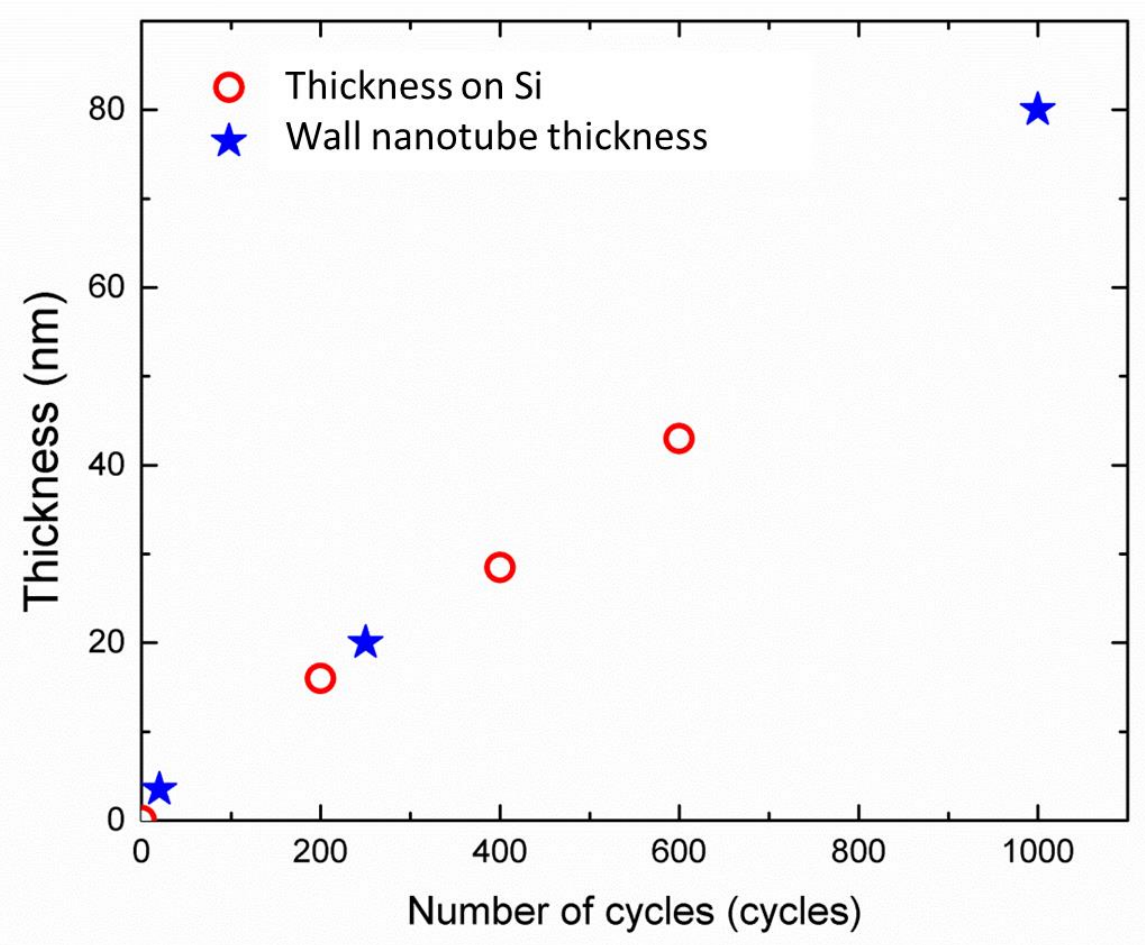

Figure S2. Wall thickness of the synthesized BN nanotubes and thickness of the BN films on Si substrates as a function of the number of ALD cycles. 